\title{
Quality measurement and nursing homes: measuring what matters
}

\author{
Robert E Burke, ${ }^{1,2}$ Rachel M Werner ${ }^{1,2}$
}

${ }^{1}$ Center for Health Equity Research and Promotion, Corporal Crescenz VA Medical Center, Philadelphia, PA, USA ${ }^{2}$ Division of General Internal Medicine, Department of Medicine, Perelman School of Medicine, University of Pennsylvania, Philadelphia, PA, USA

\section{Correspondence to} Dr Robert E Burke, Corporal Crescenz VA Medical Center, Philadelphia, PA 19104, USA; burkerob@pennmedicine.upenn. edu

Accepted 29 March 2019 Published Online First 17 April 2019

\section{SLinked}

- http://dx.doi.org/10.1136/ bmjqs-2018-008924

- http://dx.doi.org/10.1136/ bmjas-2018-009130

- http://dx.doi.org/10.1136/ bmjqs-2019-009384

\section{Check for updates}

(c) Author(s) (or their employer(s)) 2019. No commercial re-use. See rights and permissions. Published by BMJ.

To cite: Burke RE, Werner RM. BMJ Qual Saf

2019:28:520-523.
The USA has measured the quality of care delivered in nursing homes for decades. ${ }^{1}$ While these efforts represent important steps towards a more transparent and accountable health system, specific successes of these measurement efforts are more difficult to pinpoint. One consistent message from the many studies that have examined nursing home quality is that our quality measures do not always measure what matters. In this issue of BMJ Quality \& Safety, $\mathrm{Xu}$ and colleagues ${ }^{2}$ provide more evidence of the weak and unpredictable relationship between nursing home quality measures and an important patient outcome that does matter-hospitalisation. Using an expanded set of quality measures collected in Minnesota nursing homes, the authors find that the 23 metrics they examine showed neither strong nor consistent associations with risk of hospitalisation in a population of Medicaid residents-neither the overall rate of hospitalisation nor potentially preventable hospitalisations. $^{2}$ Further, while some associations were expected (eg, nursing homes with lower usage of urinary catheters had fewer hospitalisations for urinary tract infections), some were not. For instance, more antipsychotic treatment was associated with less hospital use, while 'improving bladder continence' was associated with more hospitalisations.

This timely evaluation by Xu et al occurs in the context of an important ongoing national debate about the value of quality measurement. ${ }^{3}$ On one hand, investments in electronic medical records and the rise of big data have accelerated the development of quality measures (which some have labelled the 'quality measurement industrial complex'), ${ }^{3}$ meaning more can be measured than ever before. On the other hand, little evidence demonstrates that these measurement efforts have mattered. Accumulating research suggests that tying quality measures to payment (shifting from volume to 'value' or quality) has so far resulted in disappointingly small improvements in patient outcomes and costs. ${ }^{5-9}$

How can we move to measuring what matters in nursing homes? One approach, taken by the American College of Physicians (ACP), is to systematically evaluate current quality measures and decide whether they are worth measuring. ${ }^{10}$ The ACP assessed 'validity' (the degree to which the measure captured what it aimed to measure and adequately distinguished good and poor quality) using five domains: clinical importance/impact, use in detecting overuse or underuse of care, strength of the supporting evidence base, technical issues, such as measurement reliability and the adequacy of risk adjustment, and finally the feasibility and applicability (to the provider being measured). As an example, the ACP reviewed clinical quality measures for physician participation in the new Merit-based Incentive Payment System/Quality Payment Program. This approach found roughly one-third of metrics relevant to general internal medicine were valid, one-third were not valid and one-third had uncertain validity. A review like this may be a useful first step to 'weed out' metrics that do not meet reasonable criteria for validity before adding new measures. The study by $\mathrm{Xu}$ and colleagues exemplifies the type of evidence that could inform such assessments because it increases our understanding of how tightly linked individual process measures are to outcomes that matter to patients or clinicians.

Another approach might be to emphasise the use of outcome measures over process measures. The Centers for Medicare and Medicaid Services Nursing Home Compare website's star-rating system for individual nursing homes are calculated using three aspects of quality: 
process measures (like those examined by $\mathrm{Xu}$ et al), nurse staffing (a structural measure) and inspections (focused largely on processes of care). These ratings have been critiqued because the overall star ratings are poorly correlated with outcomes such as hospitalisations, emergency department visits, patient satisfaction and rates of return to the community. ${ }^{11-15}$ However, recent legislation has broadened quality reporting to include outcomes, and Nursing Home Compare now also includes nursing homes' rates of 30-day rehospitalisation, emergency department visits and return of residents in that facility to the community. While rebalancing of Nursing Home Compare to include robust outcome measures is welcome, a useful next step would be to incorporate these outcomes into the overall star ratings on Nursing Home Compare. Additional outcome measures could also be included, such as quality of life, which is often paramount for nursing home residents but is not typically measured. Though data on quality of life remain difficult and expensive to collect, novel methods for collecting and integrating patient-reported outcomes into care plans are being explored in other settings and may hold promise. ${ }^{16}$

There is much to be gained from improving quality measurement in nursing homes for its own sake. First, more informative and meaningful measures would more effectively enable consumers to choose high-performing facilities. This could help to address the significant need for more informed decisions at hospital discharge, when patients and clinicians are choosing among nursing home options for postacute care. ${ }^{17-20}$ Second, as health systems are increasingly held accountable for the quality and costs of postacute care and seek to build partnerships with preferred nursing home providers, ${ }^{21} 22$ more robust measurement and public reporting of outcomes (such as those now reported on Nursing Home Compare) could help hospitals form effective partnerships with high-quality nursing homes.

However, making measurement matter requires commensurate investment in quality improvement for nursing home care. ${ }^{23} 24$ Measurement on its own can inform prospective nursing home residents and their families. But, ultimately, we want quality measures to stimulate improvement. Achieving such improvements requires investment. To quote a recent perspective, "Health care systems that have achieved substantial and sustained improvements in health care quality have devoted time, people, and resources to creating more reliable systems". ${ }^{25}$ Nursing homes face broad resource challenges. The average operating margin for nursing homes in the USA was zero in $2017 .^{26}$ Investment in home-based and community-based alternatives to long-term care is decreasing the longterm care population, ${ }^{27}$ while use of nursing homebased postacute care is waning under alternative payment models. The nursing home care that remains is increasingly targeted for financial penalties related to outcomes (such as readmission rates) in new valuebased purchasing programmes. ${ }^{28} 29$

This relative lack of resources poses a threat to effective quality improvement no matter how much quality measurement improves. For example, a recent trial of INTERACT, an intervention designed to reduce hospitalisations of nursing home residents, showed no apparent benefit. ${ }^{30}$ The authors contend this null result could reflect the challenges of implementing a complex, resource-intensive intervention in the nursing home setting, something noted in pre-trial studies where drop-out of nursing homes was a concern. ${ }^{31}$ A subsequent per-protocol analysis found that nursing homes able to implement the intervention saw reductions in hospitalisations, but only a minority were able to do so. ${ }^{32}$ Enlisting external support to assist nursing homes with quality improvement-such as that funded by the Centers for Medicare and Medicaid Services through the Quality Improvement Organizations (QIO) programme-may be helpful, though evaluation of the effect of QIOs remains surprisingly limited. ${ }^{33} 34$

Some interventions have achieved greater success in decreasing hospital utilisation among nursing home residents-interventions characterised by their investment in providing direct clinical care to nursing home residents. For example, the Initiative to Reduce Avoidable Hospitalizations among Nursing Facility Residents found the most effective model for reducing hospitalisations was to increase direct care provision by nurses and/or nurse practitioners. ${ }^{35}$ Similarly, bringing hospital-based personnel (physicians, nurse practitioners and pharmacists) to 'preferred' nursing home partners reduced readmissions. ${ }^{36}{ }^{37}$ Given their cost, these approaches may not be sustainable ${ }^{38}$ and ongoing work in Phase 2 of the Initiative to Reduce Hospitalizations as well as new nursing home valuebased purchasing will provide important insights into alternative methods to invest in quality improvement. ${ }^{28} 2939$

Much has been written about quality measurement in nursing homes over the years. ${ }^{140-42}$ While the issues have remained strikingly similar over time, their implications have never been more important for the postacute and long-term care of older adults in the USA and most high-income countries. Preparing for the large influx of patients who will need long-term services and supports in the coming decades requires measuring what matters, and then making that measurement matter through investment in quality improvement.

Funding RB is supported by a VA HSR\&D Career Development Award. RMW is supported by NIA K24AG047908.

Competing interests None declared.

Patient consent for publication Not required.

Provenance and peer review Commissioned; internally peer reviewed. 


\section{REFERENCES}

1 Improving the Quality of Long-Term Care-NCBI Bookshelf. Available: https://www.ncbi.nlm.nih.gov/books/NBK224500/ [Accessed 14 Feb 2019].

$2 \mathrm{Xu} \mathrm{D}$, Kane R, Arling G. The relationship between nursing home quality indicators and potentially preventable hospitalization. BMJQS 2019;28:524-33.

3 McGlynn EA, Schneider EC, Kerr EA. Reimagining quality measurement. N Engl J Med 2014;371:2150-3.

4 Editor's Notebook: Measures That Matter. Patient Safety \& Quality Healthcare. Available: https:/www.psqh.com/analysis/ measures-that-matter/ [Accessed 14 Feb 2019].

5 Lewis VA, Fisher ES, Colla CH. Explaining sluggish savings under accountable care. N Engl J Med 2017;377:1809-11.

6 Nyweide DJ, Lee W, Cuerdon TT, et al. Association of pioneer accountable care organizations vs traditional Medicare fee for service with spending, utilization, and patient experience. JAMA 2015;313:2152-61.

7 Dummit LA, Kahvecioglu D, Marrufo G, et al. Association between hospital participation in a Medicare bundled payment initiative and payments and quality outcomes for lower extremity joint replacement episodes. JAMA 2016;316:1267-78.

8 Ody C, Msall L, Dafny LS, et al. Decreases In readmissions credited to Medicare's Program to Reduce Hospital Readmissions have been overstated. Health Affairs 2019;38:36-43.

9 Burns LR, Pauly MV. Transformation of the health care industry: curb your enthusiasm? The Milbank Quarterly 2018;96:57-109.

10 MacLean CH, Kerr EA, Qaseem A. Time out-charting a path for improving performance measurement. $N$ Engl J Med 2018;378:1757-61.

11 Saliba D, Weimer DL, Shi Y, et al. Examination of the new short-stay nursing home quality measures: rehospitalizations, emergency department visits, and successful returns to the community. Inquiry 2018;55.

12 Brauner D, Werner RM, Shippee TP, et al. Does nursing home compare reflect patient safety in nursing homes? Health Affairs 2018;37:1770-8. 11.

13 Neuman MD, Wirtalla C, Werner RM. Association between skilled nursing facility quality indicators and hospital readmissions. JAMA 2014;312:1542-51.

14 Ryskina KL, Konetzka RT, Werner RM. Association between 5 -star nursing home report card ratings and potentially preventable hospitalizations. Inquiry 2018;55.

15 Johari K, Kellogg C, Vazquez K, et al. Ratings game: an analysis of nursing home compare and Yelp ratings. BMJ Qual Saf 2018;27:619-24.

16 Bradley SM, Rumsfeld JS, PM H. Incorporating health status in routine care to improve health care value: the VA patient reported health status assessment (PROST) system. JAMA 2016;316:487-8.

17 Tyler DA, Gadbois EA, McHugh JP, et al. Patients are not given quality-of-care data about skilled nursing facilities when discharged from hospitals. Health Affairs 2017;36:1385-91.

18 Konetzka RT, Perraillon MC. Use of nursing home compare website appears limited by lack of awareness and initial mistrust of the data. Health Affairs 2016;35:706-13.

19 Burke RE, Lawrence E, Ladebue A, et al. How hospital clinicians select patients for skilled nursing facilities. J Am Geriatr Soc 2017.
20 Burke RE, Jones J, Lawrence E, et al. Evaluating the quality of patient decision-making regarding post-acute care. J Gen Intern Med 2018;33:678-84.

21 Zhu JM, Patel V, Shea JA, et al. Hospitals using bundled payment report reducing skilled nursing facility use and improving care integration. Health Affairs 2018;37:1282-9.

22 Colla CH, Lewis VA, Bergquist SL, et al. Accountability across the continuum: the participation of postacute care providers in accountable care organizations. Health Serv Res 2016;51:1595-611.

23 Werner RM, Konetzka RT. Advancing nursing home quality through quality improvement itself. Health Affairs 2010;29:81-6.

24 Konetzka RT, Werner RM. Applying market-based reforms to long-term care. Health Affairs 2010;29:74-80.

25 McGlynn EA, Adams JL, Kerr EA. The quest to improve quality: measurement is necessary but not sufficient. JAMA Intern Med 2016;176:1790-1.

26 33rd Edition. Skilled nursing facility cost comparison report—an industry in transition. Available: https://www. claconnect.com/resources/white-papers/2018/-/media/files/ resources-supporting/33rd-edition-skilled-nursing-facility-costcomparison-report-cla.pdf [Accessed February 14, 2019].

27 Span P. In the nursing home, empty beds and quiet halls. The New York Times. Available: https://www.nytimes.com/2018/ 09/28/health/nursing-homes-occupancy.html [Accessed 14 Feb 2019].

28 Carnahan JL, Unroe KT, Torke AM. Hospital readmission penalties: coming soon to a nursing home near you! J Am Geriatr Soc 2016;64:614-8.

29 Burke RE, Cumbler E, Coleman EA, et al. Post-acute care reform: implications and opportunities for hospitalists. J Hosp Med 2017;12:46-51.

30 Kane RL, Huckfeldt P, Tappen R, et al. Effects of an intervention to reduce hospitalizations from nursing homes: a randomized implementation trial of the interact program. JAMA Intern Med 2017;177:1257-64.

31 Ouslander JG, Lamb G, Tappen R, et al. Interventions to reduce hospitalizations from nursing homes: evaluation of the interact II collaborative quality improvement project. J Am Geriatr Soc 2011;59:745-53.

32 Huckfeldt PJ, Kane RL, Yang Z, et al. Degree of implementation of the Interventions to Reduce Acute Care Transfers (INTERACT) quality improvement program associated with number of hospitalizations. J Am Geriatr Soc 2018;66:1830-7.

33 Stevenson DG, Mor V. Targeting nursing homes under the quality improvement organization program's 9th statement of work. J Am Geriatr Soc 2009;57:1678-84.

34 Snyder C, Anderson G. Do quality improvement organizations improve the quality of hospital care for Medicare beneficiaries? JAMA 2005;293:2900-7.

35 Ingber MJ, Feng Z, Khatutsky G, et al. Initiative to reduce avoidable hospitalizations among nursing facility residents shows promising results. Health Affairs 2017;36:441-50.

36 Rothberg MB. Impact of a connected care model on 30-day readmission rates from skilled nursing facilities. J Hosp Med 2017;12.

37 Rosen BT, Halbert RJ, Hart K, et al. The enhanced care program: impact of a care transition program on 30-day hospital readmissions for patients discharged from an acute care facility to skilled nursing facilities. J Hosp Med 2018;13:229-36. 
38 Burke R, Greysen SR. Reducing SNF readmissions: at what cost? J Hosp Med 2018;13:285-6.

39 RTI. Evaluation of the initiative to reduce avoidable hospitalizations among nursing facility residents-payment reform, First annual report. Available: https://downloads.cms. gov/files/cmmi/rahnfr-phasetwo-firstannrpt.pdf [Accessed 19 Mar 2019].
40 Wiener JM. An assessment of strategies for improving quality of care in nursing homes. The Gerontologist 2003;43(suppl_2):19-27.

41 Mor V. Defining and measuring quality outcomes in long-term care. J Am Med Dir Assoc 2007;8:e129-37.

42 Castle NG, Ferguson JC. What is nursing home quality and how is it measured? The Gerontologist 2010;50:426-42. 